\title{
Entorno latinoamericano: una lectura desde la comunicación organizacional
}

\author{
Contexto latino-americano: uma leitura \\ a partir da comunicação organizacional
}

\section{Latin American context: from} the perspective of organizational communication

E I análisis de la realidad social, política y económica de la región latinoamericana desde distintas perspectivas de la comunicación organizacional es lo que se plantea este Dossier del número 37 de la revista Organicom. Se parte de la premisa de que las organizaciones son ciudadanas activas y como tal tienen voz, y sus acciones, relaciones y discursos promueven valores e intereses que impactan las sociedades en las cuales se desenvuelven. El complejo contexto comunicativo en el que se desempeñan las organizaciones se caracteriza por la desconcentración y diversidad de fuentes informativas. Las implicaciones de estas dinámicas comunicativas son paradójicas; por un lado, han permitido un relacionamiento más directo entre organizaciones, instituciones y sus públicos, y, por otro, han evidenciado la fragilidad de organizaciones e instituciones ante fenómenos como la desinformación y mal información. En un contexto donde las crisis de confianza son cada vez más comunes entre organizaciones y sus públicos, resulta crucial reflexionar sobre el papel de la comunicación organizacional, como disciplina académica y como práctica profesional, en la construcción de dinámicas comunicativas que contribuyan a generar una mayor coherencia entre el ser y hacer de las organizaciones; y en la construcción de relaciones de confianza que sustenten sociedades más justas.

Este Dossier coordinado por las doctoras Lissette Marroquín Velásquez, de la Universidad de Costa Rica, Caroline Delevati Colpo, de la Universidade Federal da Paraíba, Claudia Labarca, de la Pontificia Universidad Católica de Chile, Ana María Suárez Monsalve, de la Universidad de Medellín y el doctor André Quiroga Sadi, de la Universidade Federal de Ouro Preto, cuenta con ocho artículos que plantean reflexiones y que se inspiraron 
ANO 18 •NÚMERO 37 SETEMBRO / DEZEMBRO 2021• ORGANICOM

ENTORNO LATINOAMERICANO: UNA LECTURA DESDE LA COMUNICACIÓN ORGANIZACIONAL

en las conversaciones sostenidas durante el Segundo Encuentro de la Red Latinoamericana de Investigación en Comunicación Organizacional (RedLaCO) intitulado "Escuchando Nuestro Entorno en América Latina: Comunicación en y de las organizaciones en tiempos turbulentos", realizado en formato virtual el 17 de noviembre del 2020.

Abrimos el Dossier con dos lecturas decoloniales de la comunicación organizacional en Latinoamérica. El texto de Erick Torrico Villanueva aborda las bases coloniales que sustentan no solo la sociedad que tenemos, sino la visión occidentalizada que movilizamos para comprender y hacer comunicación. Esta visión instrumentalizada replica la in-comunicación instaurada por el acto colonizador. Decolonizar, propone Torrico Villanueva, implica devolverle a la comunicación su condición humanizante, un aspecto vital en el desarrollo de procesos socioorganizativos. María Aparecida Ferrari, por su parte, en "Reflexiones sobre la comunicación organizacional desde América Latina: vientos de cambio en la gestión de la diversidad" presenta los desafíos que enfrentan las empresas latinoamericanas desde una perspectiva que subraya la estrecha relación entre comunicación y cultura.

Castro Torres y García Oñate nos presentan dos visiones novedosas de la comunicación estratégica. El estudio de caso de la Colegiatura Colombiana, de Castro Torres, propone un modelo de comunicación estratégica que se ajuste a la perspectiva cosmopoliética que desarrolla esta organización, que se define desde el cuidado de sí, del otro y del mundo. El marco analítico propuesto permite entender la comunicación estratégica desde una perspectiva más dialógica y relacional que desde el tradicional acercamiento funcionalista. En el artículo "Impacto social en comunidades vulnerables desde la comunicación estratégica: Aportes a la gobernabilidad y la ciudadanía", García Oñate traslada la noción de comunicación estratégica al plano de las comunidades vulnerables para el logro de la integración social. El tema se desarrolla desde la experiencia de extensión social de universidades. Estos procesos implican la vinculación directa con poblaciones para construir relaciones de confianza como base para promover el cambio social. La autora argumenta que para poner la comunicación estratégica al servicio de otros procesos socioorganizativos es necesario generar confianza y articular el conocimiento de otras áreas de la comunicación como, por ejemplo, la comunicación interpersonal, la educomunicación, entre otras.

Pacheco de Oliveira y Delevati Colpo, así como Calonego, Carareto Alves y Andrelo abordan los temas de confianza organizacional y desinformación desde la comunicación organizacional de entidades públicas y desde una iniciativa intersectorial. Pacheco de Oliveira y Delevati Colpo se preguntan: “¿Los formatos de comunicación organizacional pública utilizados en el contexto de la pandemia por covid-19 tienden a generar comunicaciones efectivas o más bien contribuyen al surgimiento de desinformación? Para ello, analizan una declaración oficial realizada por el presidente de Brasil, Jair Messias Bolsonaro, sobre la pandemia, y tres chequeos de información que circularon después de esa declaración. Las autoras identificaron que las características materiales del formato de la información pública en Brasil revelaron características compatibles con los productos de la desinformación y, por tanto, no generan confianza. Calonego, Carareto Alves y Andrelo nos invitan a explorar las implicaciones de la comunicación organizacional en la esfera pública, en el contexto de la desinformación durante la pandemia por covid-19. Las autoras analizan la estrategia de comunicación de la iniciativa brasileña Unidos por la Vacuna -los mensajes de la iniciativa en redes sociales, así como la respuesta del público-. Esta iniciativa reúne organizaciones del sector privado y del tercer sector con el objetivo de completar la vacunación de la población brasileña para setiembre del 2021. El análisis revela las tensiones que perciben los públicos entre los intereses empresariales (tener presencia en la agenda mediática) y el interés público (contar con verdaderas propuestas para mejorar el proceso de vacunación).

En "Nuevas ciudadanías y nueva capacidad de influencia en decisiones estratégicas", Suárez Monsalve y Athaydes nos presentan interesantes reflexiones sobre la capacidad de influencia de profesionales de comunicación en escenarios de toma de decisión basadas en los datos del Latin American Communication Monitor (2018). Las autoras se enfocan en la dimensión política de la comunicación organizacional al abordar la función estratégica de creación de escenarios y análisis de información de las personas profesionales en este campo como una ciudadanía política. Esta cuestión parece relevante en tiempos política y económicamente inciertos como los que vive el continente latinoamericano. 
La sección Espacio Abierto presenta los textos "Petrobras: entre hechos, informes y argumentos legitimadores", de Larissa Conceição dos Santos; "Compromiso organizacional en comunicación organizacional y relaciones públicas: análisis del uso del concepto en publicaciones científicas", de Denise Pragana Videira; y "La influencia de la comunicación interna en la innovación en las organizaciones: una revisión sistemática integradora", de Kleiton Luiz Nascimento Reis y Maria José Baldessar.

Dos Santos nos propone un análisis narrativo de la emblemática empresa brasileña Petrobras. El análisis de la historia organizacional de Petrobras a partir del macroanálisis narrativo, el análisis del discurso y el análisis retórico revelan la estrategia de comunicación a partir de la cual se construye la organización para legitimar su existencia en un contexto que cuestiona la organización por la corrupción sistémica que la aqueja. A diferencia de los textos anteriores, en que las organizaciones son víctimas de omisiones por parte de quienes construyen los mensajes, aquí el énfasis está en la selección de elementos que la organización incluye para construir su narrativa.

Videira, por su parte, estudia la presencia del concepto de compromiso organizacional en una muestra de producción académica en Brasil. La autora revisó 16 tesis y disertaciones del catálogo Capes 2013-2018 y 68 artículos publicados en la revista Organicom entre el 2004 y el 2018. El compromiso resulta una dimensión crucial de los procesos de comunicación en las organizaciones, sobre todo en el contexto actual de las crisis de confianza institucional y corporativa. A pesar de la relevancia del tema, el estudio muestra que prima el uso no científico del término, es decir, no se hace referencia a ningún concepto o teoría en específico.

Reis y Baldessar en "La influencia de la comunicación interna en la innovación en las organizaciones: una revisión sistemática integradora" realizan un estudio para verificar la influencia de la comunicación interna como elemento fundamental en la innovación en las organizaciones a partir de la revisión de publicaciones del base de datos Scopus.

En la sección Deposiciones, las autoras del artículo "Conceptos fundamentales en la formación profesional de los especialistas de la comunicación organizacional en algunas universidades del centro de México" estudiaron las variables de filosofía organizacional, cultura, vivencia cultural, comunicación estratégica, efectividad, técnicas, eficiencia, jerarquía, dirección, liderazgo, ética, ciudadanía, responsabilidad social organizacional y mejora social con líderes de programas académicos y empleadores. El estudio cualitativo realizado con entrevistas a los directores de las Licenciaturas de Comunicación de dos universidades en México (en Puebla y el estado de Hidalgo) y cuatro empleadores resalta la importancia de los valores y la ética tanto en el estudio como en la práctica de la comunicación organizacional.

La entrevista nos brinda el punto de vista de tres profesionales sobre las vacunas y las estrategias de vacunación en Latinoamérica, con énfasis en el caso de Chile, Costa Rica y Brasil. Dos de las personas entrevistadas brindan sus puntos de vista desde las ciencias de la salud y una desde la comunicación organizacional de la Caja Costarricense del Seguro Social, la institución estatal encargada de brindar los servicios de salud en Costa Rica.

Este número de Organicom termina con una reseña del libro O educador: o perfil de Paulo Freire, que retrata la trayectoria del educador e investigador Paulo Freire y presenta su legado en el año en que se conmemora el centenario de su nacimiento.

LISSETTE MARROQUINN VELÁSQUEZ CAROLINE DELEVATICOLPO

CLAUDIA LABARCA

ANA MARIA SUÁREZ MONSALVE ANDRÉQUIROGA SADI 